University of Windsor

Scholarship at UWindsor

2012

\title{
Properties of quality constructs in Canadian business relationships
}

David Hutchinson Dr.

University of Windsor

Jang Singh

University of Windsor

Follow this and additional works at: https://scholar.uwindsor.ca/odettepub

Part of the Business Commons

\section{Recommended Citation}

Hutchinson, David Dr. and Singh, Jang. (2012). Properties of quality constructs in Canadian business relationships. International Journal of Business Excellence, 5 (4), 429-443.

https://scholar.uwindsor.ca/odettepub/78

This Article is brought to you for free and open access by the Odette School of Business at Scholarship at UWindsor. It has been accepted for inclusion in Odette School of Business Publications by an authorized administrator of Scholarship at UWindsor. For more information, please contact scholarship@uwindsor.ca. 


\title{
Properties of quality constructs in Canadian business relationships
}

\section{David Hutchinson* and Jang Singh}

Odette School of Business, University of Windsor, Windsor, ON, N9B 3P4, Canada

Fax: 519-973-7073

E-mail: dhutch@uwindsor.ca_E-mail: jang@uwindsor.ca

*Corresponding author

\section{Göran Svensson and Tore Mysen}

Oslo School of Management, P.O. Box 1195, Sentrum, 0107 Oslo, Norway

E-mail: goran.svensson@hh.se_E-mail: tore.mysen@mh.no

\begin{abstract}
This paper investigates whether satisfaction, in B2B relationships, is a mediating construct between the antecedents, trust and commitment, and subsequent outcomes. Using data from a survey of Canadian managers and executives, the study tested a structural equation model, the trust, commitment, satisfaction (TCS) model, where the antecedent constructs, trust and commitment, are mediated by the satisfaction construct, which in turn influences coordination, cooperation and continuity or 'consequence' constructs. The tested model indicated an acceptable fit, validity and reliability. The analysis in the present study reinforces the argument that satisfaction plays a mediating role in creating enduring relationships in business contexts.
\end{abstract}

Keywords: business to business; B2B; relationship marketing; quality; trust; satisfaction; commitment; coordination; cooperation; continuity; Canada.

Reference to this paper should be made as follows: Hutchinson, D., Singh, J., Svensson, G. and Mysen, T. (2012) 'Properties of quality constructs in Canadian business relationships', Int. J. Business Excellence, Vol. 5, No. 4, pp.429-443.

Biographical notes: David Hutchinson is an Assistant Professor of Marketing at the Odette School of Business at the University of Windsor, with research interests in the area of business to business marketing and marketing education. He had worked in the sales and marketing area, for corporations such as $3 \mathrm{M}$ Health Care. He has since completed a $\mathrm{PhD}$ and is active in research involving simulation and gaming and customer-supplier relationship marketing. His field of research is marketing: relationship building between organisations.

Jang Singh is a Professor at the Odette School of Business, University of Windsor, Canada. While he has published in many areas, his research focus is business ethics with particular emphasis on corporate codes of ethics. His research papers have been published in several scholarly journals including Journal of World Business, Journal of Business Ethics and Business and Society Review. 
Göran Svensson is Professor at Oslo School of Management, Norway and Professor at Halmstad University, Sweden and Honorary Professor at Deakin University, Australia. He holds a $\mathrm{PhD}$ at the School of Economics and Commercial Law, Göteborg University, Sweden. He is a committed member of the international research community as journal editor, numerous editorial boards and scholarly/research networks and associations. He is the author of international journal articles and international conference contributions and engaged as a book author. He has published in areas such as business ethics, leadership, logistics, marketing, sustainability, public sector management, quality management, academic journals and publishing. He has a background as an industrialist and entrepreneur in South America.

Tore Mysen is an Associate Professor at Oslo School of Management, Norway. He holds a Dr. Oecon (PhD) at Norwegian School of Management BI. He has background as an entrepreneur and from management and board positions within telecommunication industry. His research agenda consists of various subjects within inter-firm relationships, such as: governance of foreign collaborative partners, coordination and cooperation, relationship management, relationship quality and relationship climate. He has published in various international journals. Furthermore, he is a member of editorial boards and is committed as track chair and session chair at conferences. His field of research includes relationship building between and within companies and international marketing.

\section{Introduction}

Relationships with buying firms become more important as they grow in size, especially if they limit the number of suppliers. Theron and Terblanche (2010) suggest organisations realise a strong relationship with customers has an impact on profits. The term relationship is not well defined (Blois, 2003) in the literature and is often interchangeable with the term relationship quality (Ulaga and Eggert, 2006). The dimensions of relationship quality are also not well defined in the literature, however, trust, satisfaction and commitment are generally considered to be the major factors investigated (Barry et al., 2008; Crosby et al., 1990; Hutchinson et al., 2010; Moliner et al., 2007; Palmatier et al., 2006; Roberts et al., 2003). The inter-relationship among the three dimensions appears to be in question (Hewett et al., 2002), however, trust is generally considered to be an antecedent to commitment (Barry et al., 2008; Morgan and Hunt, 1994; Ulaga and Eggert, 2006), the rationale for this being that trust must be earned to strengthen a customer's affective commitment in a business relationship or partnership.

In studies investigating the relationship between these dimensions some researchers suggest that satisfaction influences trust or commitment (Anderson and Narus, 1990; Geyskens et al., 1999; Ulaga and Eggert, 2006), or satisfaction acts as a key moderator between antecedents of commitment and trust (Ha and Muthaly, 2008). Other studies suggest that satisfaction is an outcome of commitment and/or trust dimensions (Farrelly and Quester, 2005; Payan et al., 2010; Taylor and Hunter, 2003), or as a mediator between trust and commitment dimensions (Garbarino and Johnson, 1999). In a business to business (B2B) study, Chenet et al. (2010) suggested that "service quality and trust impact on differentiation and how differentiation in turn acts on commitment and 
ultimately satisfaction and word-of-mouth communication" (p.336). According to Nyaga et al. (2010) trust and commitment are key mediating variables to relationship outcomes such as satisfaction and operational performance improvements. Recent studies suggest that satisfaction acted as a mediator between trust and commitment, and outcome dimensions (Lee et al., 2010; Svensson et al., 2010).

The primary research objective in the study presented here is to test and confirm whether satisfaction, in Canadian B2B relationships, is a mediating construct between the antecedents trust and commitment and subsequent outcomes dimensions. As indicated, there appears to be some support for satisfaction being influenced by trust and, or commitment constructs (Barclay and Smith, 1997; Farrelly and Quester, 2005; Johnson et al., 2008; Lee et al., 2010; Mohr and Spekman, 1994; Payan and Svensson, 2007; Roath and Sinkovics, 2006). In addition, as indicated by Ulaga and Eggert (2006), satisfaction appears to have a stronger association with some outcomes relative to trust or commitment constructs (Lang and Colgate, 2003; Rauyruen and Miller, 2007). Finally, Moliner et al. (2007) suggest "that the fundamental variable in a customer's perception of relationship quality is the customer's satisfaction" (p.1415). Based on review of these recent articles, satisfaction appears to be an important construct in regards to influencing subsequent outcomes than trust or commitment. Therefore, the main objective of this Canadian study was to investigate satisfaction as a mediator between trust and commitment and outcome constructs.

The preferred outcome of an investment in developing a B2B relationship would generally be the creation of a successful association. The number of outcome variables can be great. However, researchers appear to suggest that joint relationship activities between B2B organisations are essential to successful associations (Payan and Svensson, 2007). This study investigated three outcome variables that are considered joint activities. Specifically, this study includes the rarely studied combination of cooperation, coordination and continuity expectancy as outcome dimensions (Lee et al., 2010; Mysen and Svensson, 2010).

Palmatier et al. (2006) in their analysis of relationship marketing factors identified both expectation of continuity and cooperation as two outcomes of relational mediators: satisfaction, trust and commitment. They reported that the "Relational mediators have the largest combined influence on the dyadic outcome of cooperation $(r=.70)$ " [Palmatier et al., (2006), p.147], as well as an influence on continuity expectation $(r=.52)$. Ulaga and Eggert (2006) noted that in a B2B relationship satisfaction and commitment "reduces the propensity to leave" (p.231), which suggests a behavioural intention to continue the relationship. Interestingly, the study concluded that trust did not impact either the intention to expand business or the propensity to leave. Rather it acts a mediator between satisfaction and commitment and therefore acts indirectly on the propensity to leave. This literature review supports the inclusion of cooperation and continuity expectation as outcomes of the dimensions of relationship quality. In addition, this study includes the construct coordination (activities performed to achieve a goal) because it is very close in meaning to cooperation (intended willingness of organisations to work with others) yet distinct because coordination reflects behaviours and cooperation reflects the intention (Payan and Svensson, 2007).

The rest of the paper begins with a theoretical framework and associated hypotheses followed by an outline of the methodology, data analysis and empirical findings, and ends with a discussion of conclusions, limitations and suggestions for future research. 


\section{Conceptual model and hypotheses}

The following conceptual model (Figure 1) follows from the literature review and previous discussion, which suggests that satisfaction, is a mediating construct between the relationship constructs, trust and commitment, and the outcomes of continuity expectancy, cooperation and coordination. In addition, all paths are hypothesised to be positive and will be discussed as follows.

Figure 1 Conceptual model

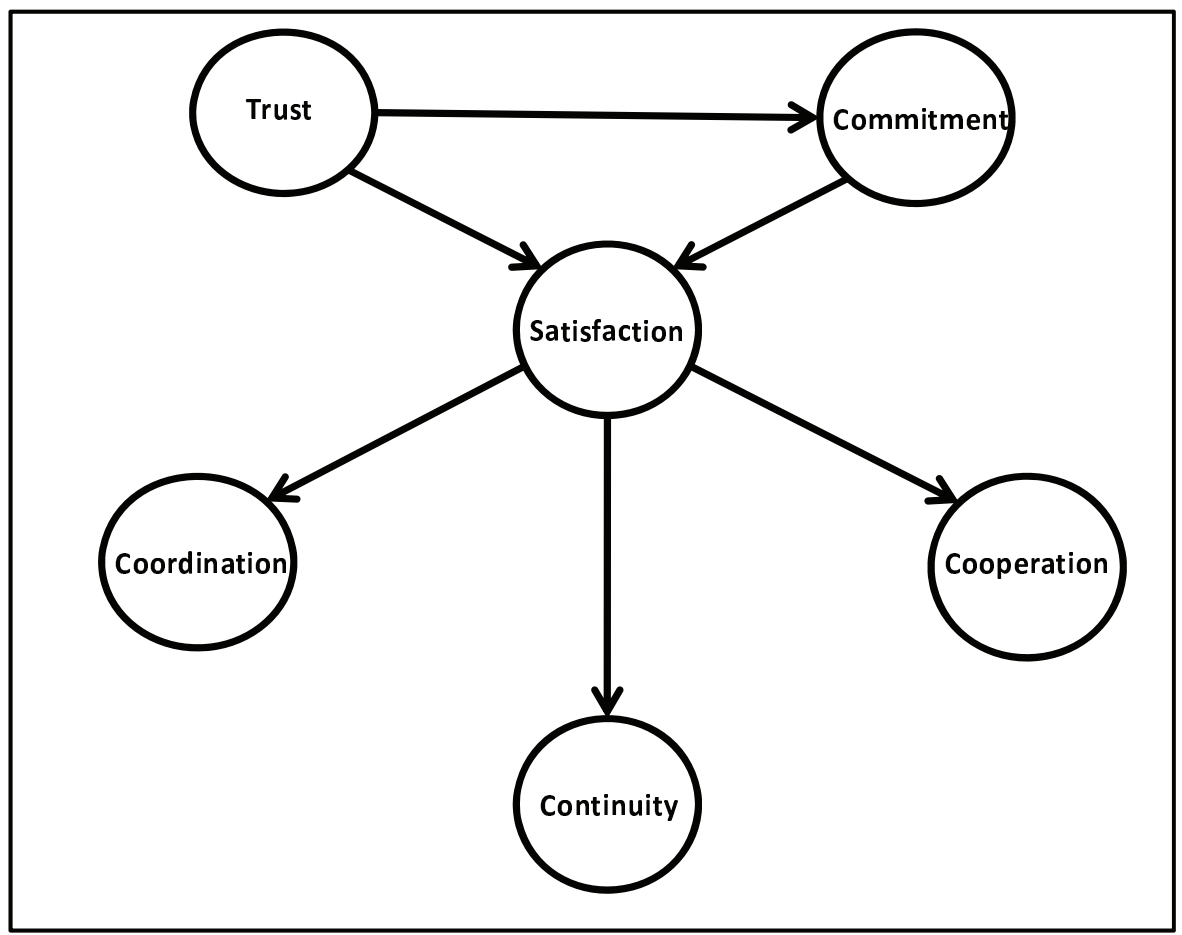

Satisfaction has been described as an affective state resulting from a judgment about how another firm performs compared to the customer's expectations (Wilson, 1995). According to Walter et al. (2003) "In market research, there is a tendency towards a cumulative view of satisfaction, measuring the general level of satisfaction based on all experiences with the firm" (p.161). In line with Andaleeb (1996) and Walter et al. (2003), the present study conceptualises satisfaction as an overall affective measure representing the manufacturer's contentment with a supplier. Commitment and trust are two of the most widely examined and confirmed constructs in relationship marketing research (Walter et al., 2003). This study defines these constructs as conceptualised by Morgan and Hunt (1994). Therefore, an employee within an organisation that trusts a supplier has confidence in the supplier's reliability and integrity while commitment to the supplier indicates that the customer believes that a relationship will be worth continuing into the future. 
Skarmeas et al. (2008) state that "...satisfaction is a focal outcome of buyer-seller relationships that is generally unlikely to develop in the absence of trust and commitment..." (p.25). Sheu et al. (2006) suggest that trust was positively related to long-term customer-supplier orientation and that the managers collaborated within the dyad, which subsequently leads to increased satisfaction overall. Wang and Huff (2007) suggest that "capability refers to whether the seller has the skills and resources necessary to perform a specific act to the buyers' satisfaction" (p.41). A trusting customer expects the vendor to communicate openly, which contributes to satisfying interactions within the dyad (Farrelly and Quester, 2005). In summary, this study hypothesises the following:

$\mathrm{H}_{1}$ Trust influences satisfaction positively.

Commitment is generally regarded as a cornerstone in developing and maintaining a B2B relationship. Morgan and Hunt (1994) write that commitment is "....an exchange partner believing that an ongoing relationship with another is so important as to warrant maximum efforts at maintaining it; that is, the committed party believes the relationship is worth working on to ensure that it endures indefinitely..." (p.23). There is evidence to suggest that the greater the level of investments made in a B2B relationship the greater the increase in that customer's commitment (Hocutt, 1998). Increasing the commitment to a relationship generally involves an increase in time and money invested in the relationship, which increases the risk. The more resources committed to a relationship might suggest more attention to details, requirements or specifications of the partnership. The clearer the supply requirements are to the vendor the easier it is to fulfil the customer's expectations, which increases the satisfaction of the buyer.

Hence, and in line with Mohr and Speckman (1994), Johnson et al. (2008) and Farrelly and Quester (2005), this study proposes that commitment in existing B2B relationships is an antecedent factor to customer satisfaction. According to Farrelly and Quester (2005) trust and commitment are key factors of satisfaction, which is a more general concept and determinant to extend or terminate a business relationship.

$\mathrm{H}_{2}$ Commitment has a positive influence on satisfaction.

It is generally accepted that trust is a precursor to commitment in a B2B exchange relationship (Gil-Saura et al., 2009; Moliner et al., 2007; Morgan and Hunt, 1994). According to Ruyter et al. (2001) "trust leads to a high level of affective commitment or, in other words, a strong desire to maintain a relationship" (p.273). Cater and Zabkar's (2009) study suggests "the dominant role of affective commitment and the non-significant role of calculative and normative commitment in marketing relationships (p.793). Morgan and Hunt (1994) also suggest that trust is important to a buyer when deciding to invest efforts into a relationship. These studies suggest that trust is a precursor to commitment in a B2B exchange relationship.

$\mathrm{H}_{3}$ Trust has a positive influence on commitment.

The conceptual model (Figure 1) in this study suggests that satisfaction acts as a mediator between trust and commitment and coordination, continuity expectation and cooperation. Mysen et al. (2012) in a forthcoming article also suggest that satisfaction acts as a mediator between trust and commitment and relationship outcomes. In support of this hypothesis, Ulaga and Eggert (2006) noted that satisfaction is widely accepted as a strong predictor of behavioural variables such as repurchase intentions, word-of-mouth, or loyalty. Their empirical study suggests that satisfaction has a stronger influence than trust 
and commitment on an organisation's decision not to leave an exchange relationship. In addition, Rauyruen and Miller's (2007) empirical study suggests that only overall satisfaction influences purchase intentions compared to trust, calculative, and affective commitment. In addition, Hutchinson et al. (2011) suggest that continuity is positively related to satisfaction and is essential in long term business relationships. Palmatier et al. (2006) also indicate that expectation of continuity as well as cooperation are outcomes of relationship satisfaction. Others have also noted that cooperation is positively correlated with satisfaction (Cambra-Fierro and Polo-Redondo, 2008; Juscius and Grigaite, 2009) in $\mathrm{B} 2 \mathrm{~B}$ exchange relationships. As indicated in the literature review, cooperation and coordination are considered conceptually different constructs (Fink and Kessler, 2010) that are closely associated and at times considered synonymous (Dabholkar et al., 1994; Payan and Svensson, 2007). Therefore, in this study, continuity expectancy (expectation of relationship duration); cooperation (willingness to work together); and coordination (joint activities between organisations) are considered outcomes that reflect the intentions and behaviours associated with working with another organisation.

$\mathrm{H}_{4}$ Satisfaction has a positive influence on coordination.

$\mathrm{H}_{5}$ Satisfaction has a positive influence on continuity expectation.

$\mathrm{H}_{6}$ Satisfaction has a positive influence on cooperation.

\section{Method}

\subsection{Research context and sample}

The measurement and structural models of relationship marketing in B2B relationships proposed in Figure 1 were tested. The models were derived from marketing theory and previous empirical research. The model suggests that the satisfaction construct is a mediator between the antecedents constructs trust and commitment and the endogenous constructs: coordination; cooperation; continuity.

The sample consisted of managers and executives in small to large sized organisations (revenue of $\$ 2$ million to 153 billion) in Canada. The data were collected in 2009 in three waves, with a determined effort to maximise participation and ensure a representative list of respondents. In the first wave, recipients of the newsletter of a national association of purchasing professionals were invited to complete an online survey. The association estimates that the newsletter is received by 7,000 persons. However, organisations may have two to three recipients of the association newsletter. A second request was sent to approximately 2,700 members of a group whose members are highly likely to also be members of the national association. In the third wave of data collection, the research instrument was sent to 774 named officers of Canada's largest corporations (with 101 of these returned as the named official had left the company). This group is also likely a subset of the national association. The data was therefore collected in a cascading manner to maximise the rate of return. This data collection process yielded 165 downloaded returns, seven letters stating that the request was forwarded to the purchasing department, eight letters indicating that it was company policy not to respond to surveys and five indicating that the addressee had left the company. Fifteen of the completed questionnaires were discarded for being incomplete or as outliers. The useable 
150 questionnaires were from respondents representing a broad cross section of Canadian purchasing professionals. Based on the experience of the researchers in similar surveys, it was believed that the response rate from busy executives and managers would be low; consequently, being granted access to a large number of potential respondents was considered a reasonable trade-off of reporting on sufficient responses versus having representativeness.

Slightly more than $38.7 \%$ of the 150 respondents were from privately owned firms and $45.3 \%$ were from publicly owned firms. The other respondents were employed in firms owned by suppliers, manufacturers, cooperatives, etc. The number of years the organisations have worked with their current supplier ranged from one to 90, with a mean of 13.6 years. Of the 150 respondents, 94 are males and 56 females. $118(78.7 \%)$ of the respondents are university educated, ten $(6.7 \%)$ reported high school as their highest level of education attained, two (1.3\%) reported grade school and 20 (13.3\%) identified 'other' as their highest level of education. The length of employment of the respondents with their current employers ranged from six months to 37 years (mean length of service was 9.4 years) and their experience in the industry ranged from six months to 38 years (mean experience was 14 years).

As suggested by Campbell (1955), the survey instrument includes two items as informant competency checks. The two items ask how much the respondent knew about his/her firm's perspective of the study topics and how much the respondent knew about specific experiences with its suppliers. A total of $98.8 \%$ of the respondents indicated that they had a good amount of knowledge about their firm's perspective in regard its suppliers and $99.4 \%$ indicated that they also had a good amount of knowledge about their firm's experiences with their suppliers. Consequently, all 150 questionnaires were used in the data analysis.

\subsection{Measures and scale items}

The sources for each construct included in the conceptual model and their respective items used in the questionnaire are as follows.

1 antecedents

- $\quad$ trust - items were adapted from Zaheer et al. (1998)

- commitment - items were adapted from Morgan and Hunt (1994) and Anderson and Weitz (1992)

2 mediator

- $\quad$ satisfaction - items were adapted from Andaleeb (1996)

3 outcome

- coordination - items were adapted from Guiltinan et al. (1980) and Heide and John (1988)

- cooperation - items were adapted from Skinner et al. (1992)

- continuity - items were adapted from Lusch and Brown (1996).

The research instrument consisted of five-point Likert-type scales for all variables. These measures were anchored at (5) strongly agree and (1) strongly disagree (see Table 1). 
Table 1 Scale items

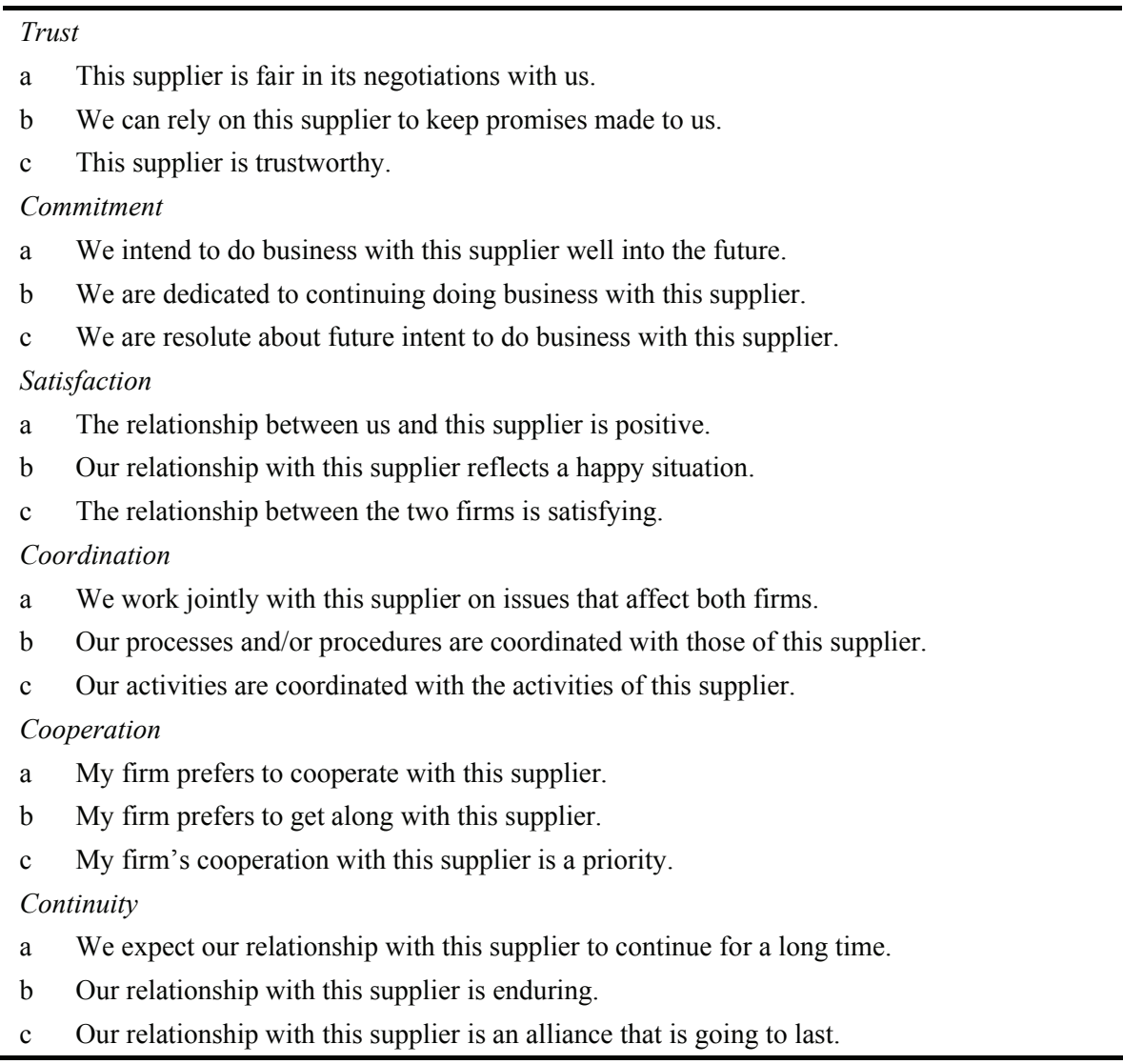

\section{Results}

\subsection{Measurement and structural models}

Confirmatory factor analysis and structural equation modelling were used to examine and test the measurement and structural properties among the constructs of the conceptual model (see Figure 1). First, a confirmatory factor analysis was run with a six construct measurement model (i.e., 18 indicator variables as shown in Figure 2) using the AMOS 17.0 software. When the measurement model was tested the goodness-of-fit measures all were found to be within the recommended guidelines [Hair et al., (2006), pp.745-749). For example, the chi-square was 195.97 with 120 degrees of freedom. This chi-square was statistically significant $(p=0.000)$ with a sample size $(N=150)$. The fit statistics are as follows: the normed chi-square $\left(X^{2} / \mathrm{df}\right)$ was 1.63 while the IFI was 0.96 , the TLI was 0.95, the CFI was 0.96, and RMSEA was 0.065 (confidence interval 90\%: 0.048-0.091). Based upon the satisfactory findings in testing the measurement model, no items were 
dropped from any of the scales and the ensuing structural model shown in Figure 2 was used to test the hypotheses.

Figure 2 Six construct structural model

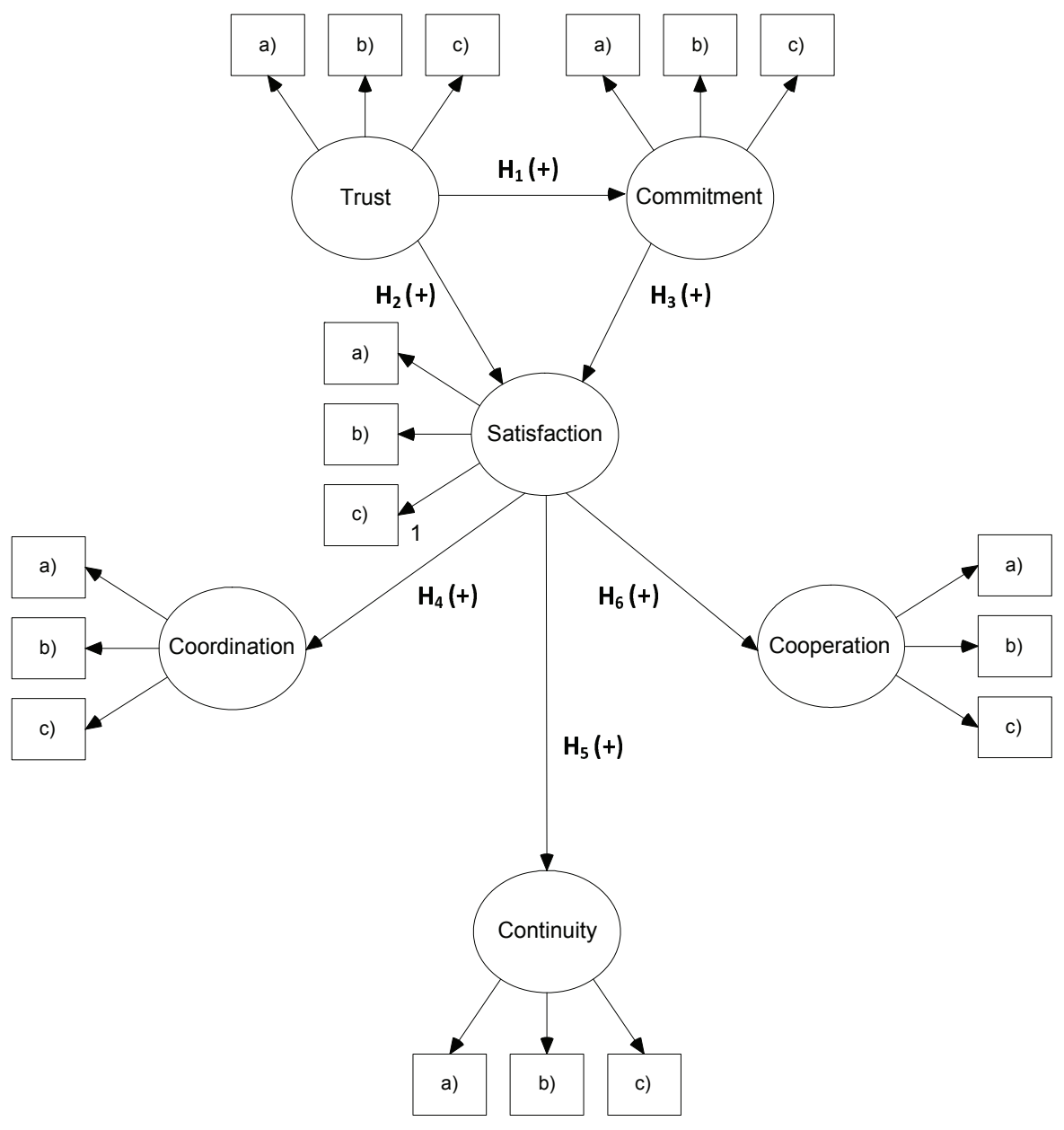

The structural model's chi-square was 279.917 with 129 degrees of freedom. This chi-square was statistically significant $(p=0.000)$. As is common practice, the other fit statistics were examined. The normed chi-square $\left(X^{2} / \mathrm{df}\right)$ was 2.17 while the IFI was 0.93 , the TLI was 0.90 , the CFI was 0.93 , and RMSEA was 0.089 (confidence interval $90 \%$ : 0.07-0.10), all of which are within recommended guidelines. The fit-statistics between the measurement and structural model differ, but this result is due to the different number of relationships in each model. In addition, the hypothesised relationships in the structural model (see Figure 2) were all significant $(p=0.000)$ having standardised regression weights ranging between $0.34-0.65$ (see Table 2). Subsequently, the findings from testing the model support all six hypotheses. 
Table 2 Tests of hypotheses

\begin{tabular}{lccccc}
\hline Hypothesis & $\begin{array}{c}\text { Exogenous } \\
\text { construct }\end{array}$ & $\begin{array}{c}\text { Endogenous } \\
\text { construct }\end{array}$ & $\begin{array}{c}\text { Regression } \\
\text { weight }\end{array}$ & Significance & Finding \\
\hline 1 & Trust & Satisfaction & 0.593 & 0.000 & Supported \\
2 & Commitment & Satisfaction & 0.340 & 0.000 & Supported \\
3 & Trust & Commitment & 0.524 & 0.000 & Supported \\
4 & Satisfaction & Coordination & 0.448 & 0.000 & Supported \\
5 & Satisfaction & Continuity & 0.647 & 0.000 & Supported \\
6 & Satisfaction & Cooperation & 0.594 & 0.000 & Supported \\
\hline
\end{tabular}

\subsection{Construct reliability and validity}

Several measures were used to assess the validity and reliability of the tested model's constructs (see Table 3). Convergent validity is the extent to which the individual items in a construct share variance between them (Hair et al., 2006) and is measured based on the variance extracted from each construct. The variance extracted for all constructs exceeded the recommended $50 \%$, with a range from $66 \%$ to $80 \%$. Reliability is also considered when evaluating constructs. All constructs exhibited composite trait reliability levels that exceed 0.7 (Hair et al., 2006), ranging between 0.84-0.89.

Table 3 Squared inter-construct correlations and summary statistics

\begin{tabular}{lcccccc}
\hline Variable & Trust & Commitment & Cooperation & Coordination & Satisfaction & Continuity \\
\hline Trust & 0.835 & & & & & \\
Commitment & 0.524 & 0.896 & & & & \\
Cooperation & 0.400 & 0.566 & 0.814 & & & \\
Coordination & 0.300 & 0.387 & 0.469 & 0.844 & & \\
Satisfaction & 0.593 & 0.608 & 0.566 & 0.412 & .891 & \\
Continuity & 0.480 & 0.775 & 0.566 & 0.470 & 0.600 & 0.862 \\
$\begin{array}{l}\text { Variance } \\
\text { extracted }\end{array}$ & $69.7 \%$ & $80.3 \%$ & $66.3 \%$ & $71.3 \%$ & $79.3 \%$ & $74.3 \%$ \\
$\begin{array}{l}\text { Composite trait } \\
\text { reliability }\end{array}$ & 0.86 & 0.86 & 0.84 & 0.88 & 0.89 & 0.88 \\
\hline
\end{tabular}

Notes: Diagonal elements are the square root of the average variance extracted (AVE) between the constructs and their measures. The off-diagonal elements are correlations between the constructs. For discriminant validity, diagonal elements should be larger than the off-diagonal elements in the same row and column.

Source: Duarte and Raposo (2010, p.467)

This study assesses whether or not the constructs are measuring different concepts (discriminant validity) by comparing the squared root of the variance extracted to the inter-construct correlations (Duarte and Raposo, 2010; Hair et al., 2006). The square root of the variance extracted should be larger than the corresponding inter-construct correlations; this condition was met in all cases (see Table 3). Consequently, the model exhibited discriminant validity. "Typically, the estimates used to judge the empirical aspects of nomological validity are measures of the strength of directional relationship, 
such as correlation coefficients" [Peter and Churchill, (1986), p.5]. In this study, the direction of the causal relationships between the constructs, is consistent with theory (see Figure 2). Also, the construct relationships were significant and consistent with theory, thus confirming nomological validity. In summary, the recommended guidelines for convergent, discriminant and nomological validity, as well as construct reliability, were all met. Therefore, the measurement and structural properties of the tested model applied in Canadian B2B exchange relationships indicate acceptable validity and reliability.

\section{Conclusions, research limitations, and future research}

This paper reports the findings of a study of quality constructs of Canadian B2B relationships between suppliers and customers. The objective of the study was to test a structural equation model, the TCS model, where the antecedent constructs trust and commitment are mediated by the satisfaction construct, which affects the coordination, cooperation and continuity or 'consequence' constructs. Based on generally accepted guidelines, the TCS model tested has indicated an acceptable fit, validity and reliability. In addition, the results support all six hypothesised relationships proposed in the TCS model.

The TCS model contributes to both theory and marketing practice in the area of business relationships. It contributes to marketing theory by testing a model, previously explored in Taiwanese business relationships, in a Canadian business context (Lee et al., 2010). Canadian national culture is presumably different from Taiwanese culture, but the significant results yielded by the analysis in the present study add support to the mediating role of satisfaction in creating enduring relationships in business contexts across national cultures. Business culture does not necessarily reflect national culture (Franke et al., 1991) and increased globalisation may contribute to the diminishing role of national cultures in $\mathrm{B} 2 \mathrm{~B}$ relationships.

The mediating role of satisfaction appears to contradict the findings of the Ulaga and Eggert (2006) study, which suggest that "trust appears ... a mediator of the satisfaction-commitment link" (p.321). The Ulaga and Eggert (2006) study was a non-representative sample of 400 purchasing managers from manufacturing organisations. They "suggest that professional buyers focus on the superiority of the supplier's offering rather than on subjective assessments of trust" [Ulaga and Eggert, (2006), p.321]. The results of this study indicate that if managers do not trust (honesty and credibility) the supplier this will negatively influence the level of commitment and satisfaction in the relationship. This suggests the relationship may not be a long term arrangement if alternative suppliers can be located. At the date of this paper, organisations from certain countries have a reputation for being less than $100 \%$ trustworthy with industrial buyers and their customers, resulting in some organisations being unsatisfied with the suppliers, which would support Ulaga and Eggert's model (2006). In other cases this low level of trust (honesty, benevolence) has prevented buyers from entering into a relationship with organisations from certain countries, which would support the results of this study. In summary, it appears there are arguments for both types of models as suggested by Farrelly et al. (2006). The study by Farrelly et al. (2006) suggested that trust in the supplier will increase the level of future commitments, and trust in future benefits (economic and non-economic) will influence the perception of future satisfaction in the relationship. 
The study is also of managerial interest as it tests a model in the areas considered to be important in the development, management and performance of business relationships. For example, the model suggests the importance of demonstrating trust (credibility and benevolence) to customers, which appears to influence satisfaction in the exchange situation and lead to a continued relationship.

Although the empirical findings of the structural equation modelling indicate an acceptable fit, validity and reliability, there are some research limitations that need to be acknowledged. For example, it should be stressed that in this study the TCS-model was tested on a sample consisting of general small, medium and large sized companies in Canada, which may indicate less applicability and generalisability to larger companies and companies in other countries or contextual settings (e.g., culture). Another limitation may be that a sample that contains a mix of companies does not cover all areas of business, nor is it equally represented across the sample. For example, it is possible that the relationship of these constructs may interact differently in specific contexts such as health care B2B situations where regulatory issues may affect the relationship. Furthermore, the model was only tested on buyer-supplier dyad relationships, whereas other kinds of business relationships (e.g., seller-buyer dyad) may possess other measurement properties and structural relationships. Implicit in the limitations of this study are suggestions for future research as studies should be designed to overcome these limitations. Nevertheless, like all survey research on a selected sample, we are confident that the TCS-model is accurate for the sample of the assorted-sized organisations examined.

The tested TCS-model may be seen as a seed for future research to refine and extend endeavours of 'antecedents' and 'consequences' in relation to satisfaction in business relationships, such as the connection to relationship value. Furthermore, it appears relevant to theory and research in the field of relationship quality.

\section{Acknowledgements}

The authors would like to acknowledge the Purchasing Management Association of Canada (PMAC), and the Propurchaser.com of Canada for their assistance in the data collection process of this study. As well as, the acknowledgement of financial assistance from the Odette School of Business for the Research \& Teaching Innovation Fund (TRIF) grant. Finally, the authors are thankful to the reviewers and editor for their time and constructive comments.

\section{References}

Andaleeb, S.S. (1996) 'An experimental investigation of satisfaction and commitment in marketing channels: the role of trust and dependence', Journal of Retailing, Vol. 72, No. 1, p.77.

Anderson, E. and Weitz, B. (1992) 'The use of pledges to build and sustain commitment in distribution channels', JMR, Journal of Marketing Research, Vol. 29, No. 1, p.18.

Anderson, J.C. and Narus, J.A. (1990) 'A model of distributor firm and manufacturer firm working partnership', Journal of Marketing, Vol. 54, No. 1, p.42.

Barclay, D.W. and Smith, J.B. (1997) 'The effects of organizational differences and trust on the effectiveness of selling partner relationships', Journal of Marketing, Vol. 61, No. 1, p.3. 
Barry, J.M., Dion, P. and Johnson, W. (2008) 'A cross-cultural examination of relationship strength in B2B services', The Journal of Services Marketing, Vol. 22, No. 2, p.114.

Blois, K. (2003) 'B2B 'relationships' - a social construction of reality? A study of Marks and Spencer and one of its major suppliers', Marketing Theory, Vol. 3, No. 1, p.79.

Cambra-Fierro, J.J. and Polo-Redondo, Y. (2008) 'Creating satisfaction in the demand-supply chain: the buyers' perspective', Supply Chain Management, Vol. 13, No. 3, p.211.

Campbell, D. (1955) 'The informant in quantitative research', American Journal of Sociology, Vol. 60, No. 4, pp.339-342.

Cater, B. and Zabkar, V. (2009) 'Antecedents and consequences of commitment in marketing research services: the client's perspective', Industrial Marketing Management, Vol. 38, No. 7, pp.785-797.

Chenet, P., Dagger, T.S. and O'Sullivan, D. (2010) 'Service quality, trust, commitment and service differentiation in business relationships', The Journal of Services Marketing, Vol. 24, No. 5, p.336.

Crosby, L.A., Evans, K.R. and Cowles, D. (1990) 'Relationship quality in services selling: an interpersonal influence perspective', Journal of Marketing, Vol. 54, No. 3, p.68.

Dabholkar, P.A., Johnston, W.J. and Cathey, A.S. (1994) 'The dynamics of long-term business-to-business exchange relationships', Journal of the Academy of Marketing Science, Vol. 22, No. 2, p.130.

Duarte, P.A.O. and Raposo, M.L.B. (2010) 'A PLS model to study brand preference an application to the mobile phone market', in Vinzi, V.E. (Ed.): Handbook of partial Least Squares: Concepts, Methods, and Applications, pp.449-485, Springer, New York.

Farrelly, F.J. and Quester, P.G. (2005) 'Examining important relationship quality constructs of the focal sponsorship exchange', Industrial Marketing Management, Vol. 34, No. 3, p.211.

Fink, M. and Kessler, A. (2010) 'Cooperation, trust and performance - empirical results from three countries', British Journal of Management, Vol. 21, No. 2, p.469.

Franke, R.H., Hofstede, G. and Bond, M.H. (1991) 'Cultural roots of economic performance: a research note', Strategic Management Journal, Vol. 12, Summer Special Issue, p.165.

Garbarino, E. and Johnson, M.S. (1999) 'The different roles of satisfaction, trust, and commitment in customer relationships', Journal of Marketing, Vol. 63, No. 2, pp.70-87.

Geyskens, I., Steenkamp, J-B.E.M. and Kumar, N. (1999) 'A meta-analysis of satisfaction in marketing channel relationships', JMR, Journal of Marketing Research, Vol. 36, No. 2, p.223.

Gil-Saura, I., Frasquet-Deltoro, M. and Cervera-Taulet, A. (2009) 'The value of B2B relationships', Industrial Management + Data Systems, Vol. 109, No. 5, pp.593-609.

Guiltinan, J., Rejab, I. and Rodgers, W. (1980) 'Factors influencing coordination in a franchise channel', Journal of Retailing, Vol. 56, No. 3, pp.41-58.

Ha, H-Y. and Muthaly, S. (2008) 'Alternative retailer-partner relationships: the role of satisfaction', International Journal of Business Excellence, Vol. 1, Nos. 1/2, p.32.

Hair, J.F., Black, W., Babin, B., Anderson, R. and Tatham, R. (2006) Multivariate Data Analysis, 6th ed., Pearson Prentice Hall, Upper Saddle River, NJ.

Heide, J.B. and John, G. (1988) 'The role of dependence balancing in safeguarding transaction-specific assets in conventional channels', Journal of Marketing, Vol. 52, No. 1, pp.20-35.

Hewett, K., Money, R.B. and Sharma, S. (2002) 'An exploration of the moderating role of buyer corporate culture in industrial buyer-seller relationships', Journal of the Academy of Marketing Science, Vol. 30, No. 3, p.229.

Hocutt, M.A. (1998) 'Relationship dissolution model: antecedents of relationship commitment and the likelihood of dissolving a relationship', International Journal of Service Industry Management, Vol. 9, No. 2, pp.189-200. 
Hutchinson, D., Singh, J., Svensson, G. and Mysen, T. (2011) 'Inter-relationships among focal dimensions in relationship quality: a quantitative and exploratory approach', International Journal of Procurement Management, Forthcoming issue.

Hutchinson, D., Wellington, W.J., Saad, M. and Cox, P. (2010) 'Refining value-based differentiation in business relationships: a study of the higher order relationship building blocks that influence behavioural intentions', Industrial Marketing Management, Doi:10.1016/j.indmarman.2010.08.010.

Johnson, M.S., Sivadas, E. and Garbarino, E. (2008) 'Customer satisfaction, perceived risk and affective commitment: an investigation of directions of influence', Journal of Services Marketing, Vol. 22, No. 5, pp.353-362.

Juscius, V. and Grigaite, V. (2009) 'Relationship marketing practice in Lithuanian logistics organizations', Baltic Journal of Management, Vol. 6, No. 1, p.71.

Lang, B. and Colgate, M. (2003) 'Relationship quality, on-line banking and the information technology gap', The International Journal of Bank Marketing, Vol. 21, No. 1, p.29.

Lee, T-R.J-S., Svensson, G. and Mysen, T. (2010) 'Antecedents' and 'postcedents' in relation to satisfaction in Taiwanese business relationships', International Journal of Procurement Management, Vol. 3, No. 2, pp.199-213.

Lusch, R.F. and Brown, J.R. (1996) 'Interdependency, contracting, and relational behavior in marketing channels', Journal of Marketing, Vol. 60, No. 4, p.19.

Mohr, J. and Spekman, R. (1994) 'Characteristics of partnership success: partnership attributes, communication behavior, and conflict resolution techniques', Strategic Management Journal, Vol. 15, No. 2, p.135.

Moliner, M.A., Sánchez, J., Rodríguez, R.M. and Callarisa, L. (2007) 'Perceived relationship quality and post-purchase perceived value', European Journal of Marketing, Vol. 41, Nos. 11/12, p.1392.

Morgan, R.M. and Hunt, S.D. (1994) 'The commitment-trust theory of relationship marketing', Journal of Marketing, Vol. 58, No. 3, pp.20-38.

Mysen, T. and Svensson, G. (2010) 'RELQUAL's impact on satisfaction in Norwegian business relationships', Journal of Business \& Industrial Marketing, Vol. 25, No. 2, pp.119-131.

Mysen, T., Svensson, G. and Lee, T.-R.J-S. (2012) 'Trust and commitment based satisfaction and the impact on specific investments, formalization and opportunism', International Journal of Business Excellence, Forthcoming issue.

Nyaga, G., Whipple, J. and Lynch, D. (2010) 'Examining supply chain relationships: do buyer and supplier perspectives on collaborative relationships differ?', Journal of Operations Management, Vol. 28, No. 2, p.101.

Palmatier, R.W., Dant, R.P., Grewal, D. and Evans, K.R. (2006) 'Factors influencing the effectiveness of relationship marketing: a meta-analysis', Journal of Marketing, Vol. 70, No. 4, p.1.

Payan, J. and Svensson, G. (2007) 'Co-operation, coordination, and specific assets in inter-organisational relationships', Journal of Marketing Management, Vol. 23, Nos. 7/8, p.797.

Payan, J.M., Svensson, G., Awuah, G., Andersson, S. and Hair, J. (2010) 'A 'cross-cultural RELQUAL-scale' in supplier-distributor relationships of Sweden and the USA', International Marketing Review, Vol. 27, No. 5, p.541.

Peter, J.P. and Churchill, G.A., Jr. (1986) 'Relationships among research design choices and psychometric properties of rating scales: a meta-analysis', JMR, Journal of Marketing Research, Vol. 23, No. 1, p.1.

Rauyruen, P. and Miller, K.E. (2007) 'Relationship quality as a predictor of B2B customer loyalty', Journal of Business Research, Vol. 60, No. 1, p.21. 
Roath, A.S., and Sinkovics, R.R. (2006) 'Utilizing relational governance in export relationships: leveraging learning and improving flexibility and satisfaction', in Carl Arthur Solberg (Ed.): Relationship Between Exporters and Their Foreign Sales and Marketing Intermediaries (Advances in International Marketing), Vol. 16, pp.157-185, Emerald Group Publishing Limited, UK.

Roberts, K., Varki, S. and Brodie, R. (2003) 'Measuring the quality of relationships in consumer services: an empirical study', European Journal of Marketing, Vol. 37, Nos. 1/2, p.169.

Ruyter, K.d., Moorman, L. and Lemmink, J. (2001) 'Antecedents of commitment and trust in customer-supplier relationships in high technology markets', Industrial Marketing Management, Vol. 30, No. 3, pp.271-286.

Sheu, C., Yen, H.R. and Chae, B. (2006) 'Determinants of supplier-retailer collaboration: evidence from an international study', International Journal of Operations \& Production Management, Vol. 26, Nos. 1/2, p.24.

Skarmeas, D., Katsikeas, C., Spyropoulou, S. and Salehi-Sangari, E. (2008) 'Market and supplier characteristics driving distributor relationship quality in international marketing channels of industrial products', Industrial Marketing Management, Vol. 37, No. 1, p.23.

Skinner, S.J., Gassenheimer, J.B. and Kelley, S.W. (1992) 'Cooperation in supplier-dealer relations', Journal of Retailing, Vol. 68, No. 2, p.174.

Svensson, G., Mysen, T. and Payan, J. (2010) 'Balancing the sequential logic of quality constructs in manufacturing-supplier relationships - causes and outcomes', Journal of Business Research, Vol. 63, No. 11, p.1209.

Taylor, S.A. and Hunter, G. (2003) 'An exploratory investigation into the antecedents of satisfaction, brand attitude, and loyalty within the (B2B) eCRM industry', Journal of Consumer Satisfaction, Dissatisfaction and Complaining Behavior, Vol. 16, p.19.

Theron, E. and Terblanche, N.S. (2010) 'Dimensions of relationship marketing in business-to-business financial services', International Journal of Market Research, Vol. 52, No. 3, pp.383-402.

Ulaga, W. and Eggert, A. (2006) 'Relationship value and relationship quality: broadening the nomological network of business-to-business relationships', European Journal of Marketing, Vol. 40, Nos. 3/4, p.311.

Walter, A., Muller, T., Helfert, G. and Ritter, T. (2003) 'Functions of industrial supplier relationships and their impact on relationship quality', Industrial Marketing Management, Vol. 32, No. 2, pp.159-169.

Wang, S. and Huff, L.C. (2007) 'Explaining buyers' responses to sellers' violation of trust', European Journal of Marketing, Vol. 41, Nos. 9/10, p.1033.

Wilson, D.T. (1995) 'An integrated model of buyer-seller relationships', Journal of the Academy of Marketing Science, Vol. 23, No. 4, pp.335-345.

Zaheer, A., McEvily, B. and Perrone, V. (1998) 'Does trust matter? Exploring the effects of interorganizational and interpersonal trust on performance', Organization Science, Vol. 9, No. 2, p.141. 